\title{
Modelling of metal hydride hydrogen compressors from thermodynamics of hydrogen - Metal interactions viewpoint: Part I. Assessment of the performance of metal hydride materials
}

\author{
Mykhaylo V. Lototskyy ${ }^{a, *}$, Volodymyr A. Yartys ${ }^{b, * *}$, Boris P. Tarasov ${ }^{c}$, \\ Moegamat Wafeeq Davids ${ }^{a}$, Roman V. Denys ${ }^{d}$, Sun Tai ${ }^{e}$ \\ a University of the Western Cape, South African Institute for Advanced Materials Chemistry, HySA Systems \\ Competence Centre, Bellville, South Africa \\ ${ }^{\mathrm{b}}$ Institute for Energy Technology, Kjeller, Norway \\ ${ }^{c}$ Institute of Problems of Chemical Physics of Russian Academy of Sciences, Chernogolouka, Russian Federation \\ ${ }^{\mathrm{d}}$ HYSTORSYS AS, Kjeller, Norway \\ e Guangdong Research Institute of Rare Metals, Guangdong Key Laboratory of Rare Earth Development and \\ Application, Guangzhou, Guangdong, China
}

\section{H I G H L I G H T S}

- Performances of metal hydrides $(\mathrm{MH})$ for thermally driven $\mathrm{H}_{2}$ compressors are modelled.

- PCT characteristics of metal- $\mathrm{H}_{2}$ systems are used as an input to the modelling.

- Modelling results are defined by the Pressure-Temperature conditions of the $\mathrm{MH}$.

- Deriving cycle productivity of MH materials and heat consumption for the compression.

\section{A R T I C L E I N F O}

\section{Article history:}

Received 15 August 2020

Received in revised form

4 October 2020

Accepted 12 October 2020

Available online 4 November 2020

\footnotetext{
* Corresponding author.

** Corresponding author
}

E-mail addresses: mlototskyy@uwc.ac.za (M.V. Lototskyy), volodymyr.yartys@ife.no (V.A. Yartys). https://doi.org/10.1016/j.ijhydene.2020.10.090 0360-3199/@ 2020 Hydrogen Energy Publications LLC. Published by Elsevier Ltd. All rights reserved.
G R A P H I A L A B S T R C T

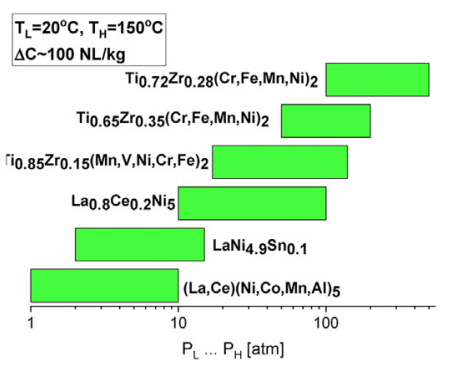

A B S T R A C T

This work presents a model to determine productivity and heat consumption of hydrogen compression utilising metal hydrides $(\mathrm{MH})$ by using Pressure - Composition - Temperature (PCT) diagrams of the $\mathrm{MH}$ materials at defined operating conditions - temperatures and hydrogen pressures. The present Part $I$ is focused on the analysis of hydrogen compression performances of several $\mathrm{AB}_{5}$ - and $\mathrm{AB}_{2}$-type intermetallic alloys which, when operating between temperatures of 20 and $150{ }^{\circ} \mathrm{C}$, provide $\mathrm{H}_{2}$ compression up to $500 \mathrm{~atm}$, with a cycle productivity about $100 \mathrm{NL} \mathrm{H}_{2} / \mathrm{kg} \mathrm{MH}$ and compression ratio of up to 10 , at $\mathrm{H}_{2}$ suction pressure below 10-15 atm, or up to 5 at higher suction pressures. 
Keywords:

Metal hydrides

Hydrogen compression

Modelling

Thermodynamics

PCT Diagram
We show that calculated cycle productivities of hydrogen compression are related to the operating conditions and significantly vary for the different $\mathrm{MH}$ materials, even though showing similar trends in their changes. The cycle productivity of $\mathrm{MH}$ material increases with decrease of the cooling temperature, decrease of the discharge pressure, increase of the heating temperature and increase of the suction pressure. When hydrogen pressure approaches plateau pressures for $\mathrm{H}_{2}$ absorption at cooling or $\mathrm{H}_{2}$ desorption at heating, the changes of the cycle productivity become very pronounced. Particularly, the compression productivity becomes very sensitive to the P-T variations when the isotherms show presence of "flat" pressure plateaux which are characteristic for the ideal PCT diagrams of the $\mathrm{MH}$. Thus, in the latter case, even minor changes in P-T result in a dramatic variation of the cycle productivity and when aiming at increased efficiency of the process, a strict P-T control is required.

(c) 2020 Hydrogen Energy Publications LLC. Published by Elsevier Ltd. All rights reserved.

\section{Introduction}

Use of the efficient and environment friendly energy storage involving hydrogen and fuel cells, is a promising path in the development of future energy technologies. Recently, special attention has been paid to the portable, vehicular and stationary hydrogen energy systems which utilise metal hydrides $(\mathrm{MH})$ for on-site storage of hydrogen, as well as for the storage and conversion of low- and medium-grade heat [1-5].

Hydrogen compression is an important component of hydrogen energy systems and is used for on-site storage of compressed hydrogen gas, the most frequently used $\mathrm{H}_{2}$ storage technology, as well as for the refuelling of fuel cell vehicles [6-8].

Among various hydrogen compression methods [8], thermally driven hydrogen compression utilising $\mathrm{MH}$ is particularly promising due to a number of advantages including high purity of the delivered hydrogen and a possibility to utilise waste heat for hydrogen compression, together with absence of moving parts (solid or liquid pistons or diaphragms), simplicity of design and operation [9-15].

Fundamentals and the most important applications of the metal hydride compression were considered in our reviews $[9,10]$. It was shown that the optimisation of the performances of a metal hydride compressor (MHHC), first of all, tailoring their operating $\mathrm{H}_{2}$ pressure range, increasing their efficiency and productivity, requires to properly account the characteristics of the utilised $\mathrm{MH}$ materials, to optimize design and technological features and operating conditions.

For a single-stage hydrogen compression operating between the temperatures $T_{L}$ to $T_{H}$ and $H_{2}$ pressures from $P_{L}$ to $P_{H}$, the cycle productivity is defined by a reversible hydrogen storage capacity of the material, $\Delta C$ :

$\Delta C=C_{A}\left(P_{L}, T_{L}\right)-C_{D}\left(P_{H}, T_{H}\right) ;$

where $C_{A}$ and $C_{D}$ are the equilibrium hydrogen concentrations in the $\mathrm{MH}$ for hydrogen absorption and desorption, respectively. Equilibrium dependencies between hydrogen pressure $(P)$ and temperature $(T)$ are described by the PressureComposition-Temperature (PCT) diagram of the hydrogen- metal system [10,16] (see Fig. 1). Consequently, the productivity of compression, $\mathrm{V}$, can be determined as:

$\mathrm{V}=\frac{m \Delta \mathrm{C}}{\Delta \mathrm{t}}$

where $m$ is the weight of the $\mathrm{MH}$ material and $\Delta t$ is the time of the $\mathrm{H}_{2}$ absorption - desorption cycle.

Instead of time-consuming experimental measurements of multiple sets of isotherms at variable $T_{L}$ and $T_{H}$ to determine $\Delta C$, use of a modelled PCT diagram covering relevant ranges of temperatures and pressures is very useful. Such a diagram is modelled by firstly fitting the available experimental data and then by calculating the absorption and desorption isotherms at the required conditions from the determined thermodynamic parameters of the system. Such approach was used by Galvis E et al. [17] and was adopted

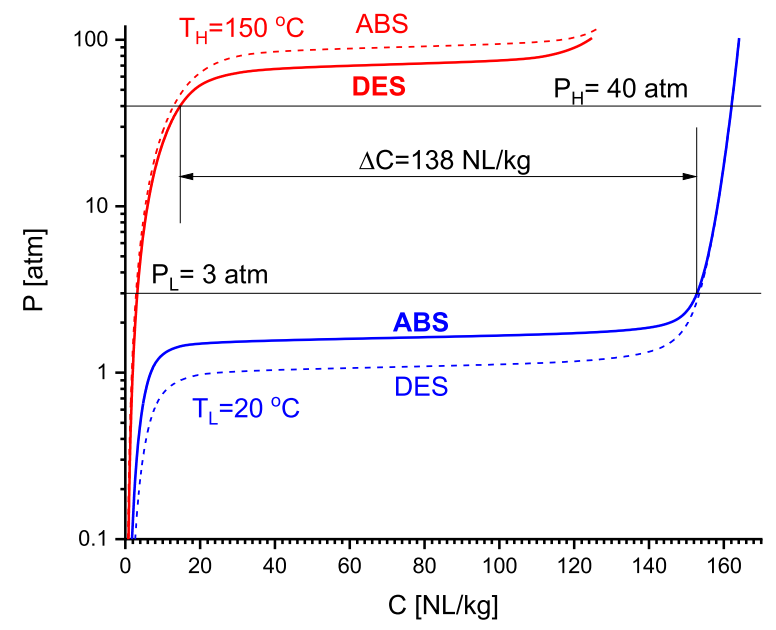

Fig. 1 - Determination of reversible hydrogen storage capacity/cycle productivity for the $\mathrm{H}_{2}$ compression using $\mathrm{LaNi}_{5}$ MH alloy. The fitted isotherms for $\mathrm{H}_{2}$ absorption (ABS) and desorption (DES) are based on the experimental data [20] which were fitted by the PCT model [21]. The cycle productivity of $138 \mathrm{NL} / \mathrm{kg}$ is a difference between the charge capacity at $\mathrm{T}_{\mathrm{L}}$ and $\mathrm{P}_{\mathrm{L}}$ and the discharge capacity at $\mathrm{T}_{\mathrm{H}}$ and $\mathrm{P}_{\mathrm{H}}$. 
during simulation of a three-stage MHHC. The used PCT model was developed by Zhou et al. $[18,19]$ and took into account such features of non-ideal isotherms as sloping plateaux and hysteresis. Consequently, the MHHC using three $\mathrm{AB}_{2}$-type alloys providing $\mathrm{H}_{2}$ compression from $\mathrm{P}_{\mathrm{L}} \approx 2$ bar $\left(\mathrm{T}_{\mathrm{L}}\right.$ $\left.=23{ }^{\circ} \mathrm{C}\right)$ to $P_{H} \approx 180$ bar $\left(T_{H}=132{ }^{\circ} \mathrm{C}\right.$ ) were tailored towards operation temperatures, weight of the $\mathrm{MH}$ and volume of its containment at each stage.

Further development of the above-mentioned approach will provide the data concerning influence of the process parameters $\left(T_{L}, T_{H}, P_{L}, P_{H}\right)$ on the productivity of single- and multi-stage MHHC's. This will allow to properly design the compressor from the viewpoint of selection of the $\mathrm{MH}$ materials and their amounts while the process parameters can vary within the specified $\mathrm{P}-\mathrm{T}$ range.

However, it appears that application of the modelling procedure [17] incorporating PCT approximation [18,19] is difficult for a number of practically important cases. The considered model is unsuitable to correctly describe the area of the PCT diagrams where $\alpha \rightarrow(\alpha+\beta)$ and $(\alpha+\beta) \rightarrow \beta$ transitions take place. This issue becomes particularly challenging when PCT diagram contains several plateau segments (particularly important for the multiphase MHs) or when operation temperature approaches critical temperature for the $\mathrm{MH}$. As a result, the accuracy of $\Delta C$ calculations becomes insufficient.

In the current study, we consider the application of our earlier developed model of phase equilibria in the metal hydrogen systems [21] for modelling of the performances of MHHC's. The model [21] while being semi-empirical, allows to estimate temperature dependencies of the "boundary" hydrogen concentrations in the $\alpha$-solid solution and $\beta$-hydride with a high accuracy. Importantly, it is able to simultaneously fit both hydrogen absorption and desorption experimental PCT data using the same set of the fitting parameters and is suitable even for the evaluation of incomplete experimental data sets.

Analysis of the application of the model [21] for the calculation of performances of hydrogen storage and compression systems utilising various $\mathrm{MH}$ materials has been presented in our recent publication as related to the operating temperatures and hydrogen pressures [22]. The present paper describes further details of the modelling and is focusing on evaluation of the effect of the changes in the pressures and temperatures on the productivity. Part I presents analysis of hydrogen compression performances of several intermetallic hydride forming materials used for the development of $\mathrm{MH}$ based hydrogen compression systems.

Application of the PCT modelling also allows to estimate heat consumption required to achieve the $\mathrm{H}_{2}$ compression, via calculation of concentration-dependent partial molar enthalpies of $\mathrm{H}_{2}$ desorption. Though the PCT-derived heat consumption data deviate from the calorimetrically derived values [23], the deviations are reasonable (see Supplementary Information file, Section S1) validating the developed approach.

\section{Materials and methods}

\section{MH materials and their PCT properties}

The data characterising three $A_{2}$ - and six $A B_{5}$-type intermetallic alloys, which were used in the development of industrial-scale MHHC's at the authors' institutions $[14,16,20,24,25]$, are listed in Table 1 . Table 1 also presents the most important experimentally measured hydrogen sorption properties of these materials including maximum hydrogen absorption capacity as related to the temperatures and hydrogen pressures, entropy and enthalpy changes during $\mathrm{H}_{2}$ desorption calculated from the van't Hoff dependencies at the plateau midpoints, as well as the calculated hydrogen compression performances.

As performance of MHHC utilising $\mathrm{LaNi}_{5}$ was found to be very sensitive to the number of hydrogen absorption/desorption cycles, we included in Table 1 the data for both asdelivered alloy and the same material cycled 10 times during the operation of the MHHC [20].

The PCT properties of the MH materials were measured using volumetric Sieverts-type setups. The used experimental conditions are specified in the Table 1.

According to the data of the XRD studies, all used alloys contained a title intermetallic phase as the major component (98.5-100 wt\%): $\mathrm{CaCu}_{5}$-type, space group P6/mmm (\#191) for $\mathrm{AB}_{5}$ and C14- (MgZn $\mathrm{M}_{2}$-type; space group $\mathrm{P}_{3} / \mathrm{mmc}$ (\#194)) Laves phase for $A_{2}$ alloys. The unit cell parameters of the major phases well agreed with the reference data.

Cyclic hydrogenation/dehydrogenation experiments resulted in line broadening on the XRD patterns indicating decrease of the crystallite size and appearance of strains; this effect was more pronounced for the $\mathrm{AB}_{5}$-type materials. The $\mathrm{LaNi}_{5}$ alloy after multiple ( 19000 times) $\mathrm{H}_{2}$ absorption/ desorption cycles showed its partial disproportionation resulting in the formation of the metallic $\mathrm{Ni}$ and a binary $\mathrm{LaH}_{2+\mathrm{x}}$ hydride while for the Ce-substituted $\mathrm{LaNi}_{5}$ the disproportionation was not observed [20].

\section{Modelling}

\section{Pressure - composition isotherms}

All experimental sets of the measured PCT data were processed by the model [21]. Within the model, the pressure composition isotherms are constructed as pseudoconvolutions of "ideal" isotherms (derived from $\mathrm{H}-\mathrm{M}$ phase diagram built assuming that $\mathrm{H}$ atoms in the metal matrix behave as a lattice gas) while applying in addition two modified asymmetric pseudo Voight distribution functions (for $\mathrm{H}$ desorption and absorption). This allows to properly model the plateau slope and hysteresis. When applying the model, the median of the absorption distribution is shifted as compared to the desorption distribution towards the higher pressures; the shift is related to the free energy loss due to hysteresis and an excessive chemical potential of hydrogen in the over- 
Table 1 - Characteristics of the studied $A_{5}$ and $A_{2}$ MH materials for $H_{2}$ compression.

\begin{tabular}{|c|c|c|c|c|c|c|c|c|c|}
\hline \multirow[t]{2}{*}{ Material [Reference] } & \multirow[t]{2}{*}{$\begin{array}{l}\text { Temperature }\left[{ }^{\circ} \mathrm{C}\right] \\
\text { (pressure }[a t m] \text { ) ranges of } \\
\text { experimental PCT data }\end{array}$} & \multirow[t]{2}{*}{$\begin{array}{c}\text { MAX H capacity } \\
{[\mathrm{NL} / \mathrm{kg}]} \\
\left(\mathrm{T}_{\mathrm{L}}\left[{ }^{\circ} \mathrm{C}\right], \mathrm{P}_{\mathrm{L}}[\text { atm }]\right)\end{array}$} & \multirow[t]{2}{*}{$\begin{array}{c}-\Delta \mathrm{S}^{\circ}[\mathrm{J} / \\
\left.\left(\mathrm{molH}_{2} \mathrm{~K}\right)\right]\end{array}$} & \multirow[t]{2}{*}{$\begin{array}{c}-\Delta \mathrm{H}^{\circ} \\
{[\mathrm{kJ} /} \\
\left.\mathrm{molH}_{2}\right]\end{array}$} & \multicolumn{2}{|c|}{$\begin{array}{l}\text { Plateau: pressure }[\mathrm{atm}]\left(\mathrm{C}_{\max } * \mathrm{~d}(\mathrm{ln} \mathrm{l}) /\right. \\
\mathrm{dC})^{\mathrm{a}}\end{array}$} & \multicolumn{3}{|c|}{$\begin{array}{c}\mathrm{H}_{2} \text { compression } \\
\text { performances } \\
\left(\mathrm{T}_{\mathrm{L}}=20^{\circ} \mathrm{C}, \mathrm{T}_{\mathrm{H}}=150^{\circ} \mathrm{C}\right)\end{array}$} \\
\hline & & & & & $\begin{array}{l}\text { Absorption at } \\
\mathrm{T}_{\mathrm{L}}=20^{\circ} \mathrm{C}\end{array}$ & $\begin{array}{l}\text { Desorption at } \\
\mathrm{T}_{\mathrm{H}}=150^{\circ} \mathrm{C}\end{array}$ & $\begin{array}{l}\mathrm{P}_{\mathrm{L}} \ldots \mathrm{P}_{\mathrm{H}} \\
{[\mathrm{atm}]}\end{array}$ & $\begin{array}{c}\Delta \mathrm{C}[\mathrm{NL} / \\
\mathrm{kg}]\end{array}$ & $\begin{array}{c}\mathrm{q}[\mathrm{kJ} / \mathrm{mol} \\
\left.\mathrm{H}_{2}\right]\end{array}$ \\
\hline $\begin{array}{l}(\mathrm{La}, \mathrm{Ce})(\mathrm{Ni}, \mathrm{Co}, \mathrm{Mn}, \mathrm{Al})_{5}[\mathrm{This} \\
\text { work] }\end{array}$ & $\begin{array}{l}20 \ldots 120 \\
(0.1 \ldots 30)\end{array}$ & $\begin{array}{l}145 \\
(20,10)\end{array}$ & 112.20 & 35.61 & $\begin{array}{l}0.382 \\
(1.16)\end{array}$ & $\begin{array}{l}26.5 \\
(1.51)\end{array}$ & $1 \ldots 10$ & 109 & 36.17 \\
\hline $\mathrm{LaNi}_{4.9} \mathrm{Sn}_{0.1}[16]$ & $\begin{array}{l}20 \ldots 120 \\
(0.1 \ldots 100)\end{array}$ & $\begin{array}{l}153 \\
(20,10)\end{array}$ & 108.30 & 32.80 & $\begin{array}{l}0.906 \\
(0.68)\end{array}$ & $\begin{array}{l}32.1 \\
(1.26)\end{array}$ & $2 \ldots 15$ & 97 & 33.14 \\
\hline $\mathrm{LaNi}_{5}[20] \quad$ As delivered & $\begin{array}{l}20 \ldots 90 \\
(0.2 \ldots 20)\end{array}$ & $\begin{array}{l}157 \\
(25,10)\end{array}$ & 113.68 & 33.04 & $\begin{array}{l}1.66 \\
(0.14)\end{array}$ & $\begin{array}{l}69.7 \\
(0.24)\end{array}$ & $3 \ldots 35$ & 140 & 34.88 \\
\hline Cycled & $\begin{array}{l}20 \ldots 90 \\
(1 \ldots 50)\end{array}$ & $\begin{array}{l}160 \\
(20,10)\end{array}$ & 84.70 & 23.99 & $\begin{array}{l}2.72 \\
(0.13)\end{array}$ & $\begin{array}{l}28.7 \\
(0.21)\end{array}$ & $4 \ldots 30$ & 53 & 30.11 \\
\hline $\mathrm{La}_{0.92} \mathrm{Ce}_{0.08} \mathrm{Ni}_{5}$ [This work] & $\begin{array}{l}20 \ldots 120 \\
(1 \ldots 150)\end{array}$ & $\begin{array}{l}150 \\
(20,30)\end{array}$ & 115.33 & 30.67 & $\begin{array}{l}6.44 \\
(1.46)\end{array}$ & $\begin{array}{l}162 \\
(1.29)\end{array}$ & $10 \ldots 50$ & 82 & 31.09 \\
\hline $\mathrm{La}_{0.8} \mathrm{Ce}_{0.2} \mathrm{Ni}_{5}[16]$ & $\begin{array}{l}10 \ldots 120 \\
(0.1 \ldots 150)\end{array}$ & $\begin{array}{l}170 \\
(20,25)\end{array}$ & 108.30 & 32.80 & $\begin{array}{l}7.15 \\
(0.44)\end{array}$ & $\begin{array}{l}109 \\
(0.66)\end{array}$ & $10 \ldots 100$ & 106 & 29.25 \\
\hline $\begin{array}{l}\mathrm{Ti}_{0.85} \mathrm{Zr}_{0.15}(\mathrm{Mn}, \mathrm{V}, \mathrm{Ni}, \mathrm{Cr}, \mathrm{Fe})_{2} \\
{[26]}\end{array}$ & $\begin{array}{l}20 \ldots 60 \\
(0.1 \ldots 100)\end{array}$ & $\begin{array}{l}210 \\
(20,90)\end{array}$ & 109.68 & 26.61 & $\begin{array}{l}13.7 \\
(0.60)\end{array}$ & $\begin{array}{l}248 \\
(0.83)\end{array}$ & 15...150 & 95 & 25.76 \\
\hline $\mathrm{La}_{0.5} \mathrm{Ce}_{0.5} \mathrm{Ni}_{5}[20]$ & $\begin{array}{l}0 \ldots 50 \\
(2 \ldots 100)\end{array}$ & $\begin{array}{l}145 \\
(20,50)\end{array}$ & 104.16 & 25.16 & $\begin{array}{l}29.7 \\
(0.48)\end{array}$ & $\begin{array}{l}202 \\
(0.31)\end{array}$ & $40 \ldots 150$ & 111 & 26.09 \\
\hline $\begin{array}{l}\mathrm{Ti}_{0.65} \mathrm{Zr}_{0.35}(\mathrm{Cr}, \mathrm{Fe}, \mathrm{Mn}, \mathrm{Ni})_{2} \\
{[16]}\end{array}$ & $\begin{array}{l}-25 \ldots 75 \\
(0.1 \ldots 180)\end{array}$ & $\begin{array}{l}190 \\
(-25,130)\end{array}$ & 103.23 & 19.66 & $34.2(0.89)$ & $375(1.24)$ & $50 \ldots 200$ & 115 & 21.49 \\
\hline $\begin{array}{l}\mathrm{Ti}_{0.72} \mathrm{Zr}_{0.28}(\mathrm{Cr}, \mathrm{Fe}, \mathrm{Mn}, \mathrm{Ni})_{2} \\
\text { [This work] }\end{array}$ & $\begin{array}{l}-20 \ldots 20 \\
(1 \ldots 120)\end{array}$ & $\begin{array}{l}190 \\
(-20,65)\end{array}$ & 115.33 & 24.85 & $\begin{array}{l}48.3 \\
(0.86)\end{array}$ & $\begin{array}{l}661 \\
(1.74)\end{array}$ & $100 \ldots 500$ & 114 & 23.68 \\
\hline
\end{tabular}


saturated $\alpha$-solid solution. The PCT diagram as a whole is described by a set of parameters (16 per one plateau segment; see Table S1) some of which (e.g. critical temperature, hysteresis energy loss, enthalpy and entropy of hydride formation) have a great value in the characterisation of the $\mathrm{MH}$ and have a clear physical meaning, while some other parameters describing temperature- and concentration-dependent plateau slope, are semi-empirical and are determined by numerical simulations and refinements.

The $\mathrm{H}-\mathrm{M}$ phase diagram was described by the "core model" of van der Waals lattice gas. The plateau pressures for $\mathrm{H}_{2}$ absorption and desorption at the cooling $\left(\mathrm{T}_{\mathrm{L}}\right)$ and heating $\left(T_{H}\right)$ temperatures (Table 1) were calculated for hydrogen concentrations in the plateau "midpoint" defined as $1 / 3$ of the asymptotic limiting $\mathrm{H}$ concentration on forming am $\mathrm{H}$ saturated hydride.

A brief description of the modelling procedure [21], together with the results of the fitting of some experimental datasets, are presented in Supplementary Information, section S2.

Heat consumption for hydrogen compression

The total heat consumption, $\mathrm{Q}$ of $\mathrm{H}_{2}$ compression cycle can be estimated by the integration of concentration dependence of partial molar enthalpy for the desorption process, $\overline{\Delta H_{D}}(C)$, in the corresponding range of hydrogen concentrations in the $\mathrm{MH}$ :

$Q=\int_{C_{D}}^{C_{A}} \overline{\Delta H_{D}}(C) d C ;$

The integration limits $C_{A}$ and $C_{D}$ were calculated using PCT model for the $\mathrm{MH}$ material as:

$C_{A}=C_{A}\left(P_{L}, T_{L}\right)$

$C_{D}=C_{D}\left(P_{H}, T_{H}\right)$

The partial molar enthalpies were calculated according to the differential form of the van't Hoff equation:

$\frac{d \ln (P)}{d(1 / T)}=-\frac{\overline{\Delta H_{D}}}{R}$.

First, the hydrogen concentration limits for the $\mathrm{H}_{2}$ desorption were determined (Eq. (4)). This procedure was followed by the calculation of the equilibrium pressures for $\mathrm{H}_{2}$ desorption by applying the PCT model in the form:

$P=P_{D}(C, T)$.

The calculations (Eq. (6)) of the series of the equilibrium pressures, $P_{j}$, were carried out for several values of temperatures equally distributed in the interval $T_{L} \leq T_{j} \leq T_{H}$. Each series $\left(P_{j}, T_{j}\right)$ was calculated at a fixed hydrogen concentration, $C_{D} \leq C_{k} \leq C_{A}$ followed by the linear fitting of the ln $P-1 / T$ dependence:

$$
\begin{gathered}
Y=A+B \cdot X \\
Y=\ln (P) \\
X=\frac{1}{T}
\end{gathered}
$$

The partial molar enthalpy at $C=C_{k}$ was further calculated as:

$\overline{\Delta H_{k}}=B \cdot R$.

For numerical integration (Eq. (3)), the trapezoid rule was applied. In doing so, we calculated $\overline{\Delta H_{k}}$ (Eqs (7) and (8)) in $\mathrm{N}$ points of the interval $C_{D} \leq C_{k} \leq C_{A}$ with the uniform step equal to:

$\delta C=\frac{C_{A}-C_{D}}{N-1}$.

Accordingly, the total heat consumption will be calculated as:

$\mathrm{Q} \approx \delta C \cdot m \cdot\left(\frac{{\overline{\Delta H_{1}}}_{2} \overline{\Delta H}_{N}}{2}+\sum_{k=2}^{N-1} \overline{\Delta H}_{k}\right)$

where $m$ is the weight of the $\mathrm{MH}$ material.

A specific heat for hydrogen compression, q, will be equal to:

$q=\frac{Q}{m \cdot\left(C_{A}-C_{D}\right)}$

Taking into account Eq. (9) and Eq. (10), Eq. (11) can be rewritten as:

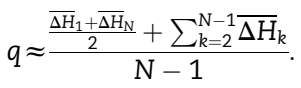

The values of the specific heat, $q$, for hydrogen compression were calculated using Eq. (4), (6-8), (12). The numbers of points in the concentration and the temperature grids were set to $N=50$ and 10 , respectively. The specified numbers corresponded to the empirically determined optimum providing sufficient accuracy (about $\pm 0.05-0.1 \mathrm{~kJ} / \mathrm{mol} \mathrm{H}_{2}$ ).

\section{Results and discussion}

\section{Hydrogen compression performances of $\mathrm{MH}$ materials}

Fig. 2(a-d) shows selected maps of the calculated cycle productivities for $\mathrm{AB}_{5}$-type $\mathrm{MH}$ used for the hydrogen compression starting from a low pressure of around 2 bar $\mathrm{H}_{2}$ as related to the operating temperatures $(a)$ and pressures $(b-d)$. Further details are presented in Supplementary Information, Section S3 (Fig. S8).

A typical general trend is illustrated by the maps for $\mathrm{LaNi}_{4.9} \mathrm{Sn}_{0.1}$ (Fig. 2(a), Figs. S8(c and d)) built in a broad pressure - temperature range (PCT data is given in Fig. S3). When the heating temperature $\left(T_{H}\right)$ increases and/or the discharge pressure $\left(P_{H}\right)$ decreases, this results in lowering of the hydrogen concentration at the discharge conditions, $C_{D}\left(P_{H}\right.$,$\left.T_{H}\right)$. Furthermore, when charging with $H_{2}, C_{A}\left(P_{L}, T_{L}\right)$ increases with the increase of $P_{L}$ and decrease of $T_{L}$. Consequently, the reversible hydrogen sorption capacity or cycle productivity, $\Delta C$ (Eq. (1)), will increase.

Though a noticeable degradation of hydrogen sorption capacity of $\mathrm{LaNi}_{5}$ because of its disproportionation occurs only after several thousand $\mathrm{H}_{2}$ absorption/desorption cycles, the altering of its PCT properties as related to the history of the 


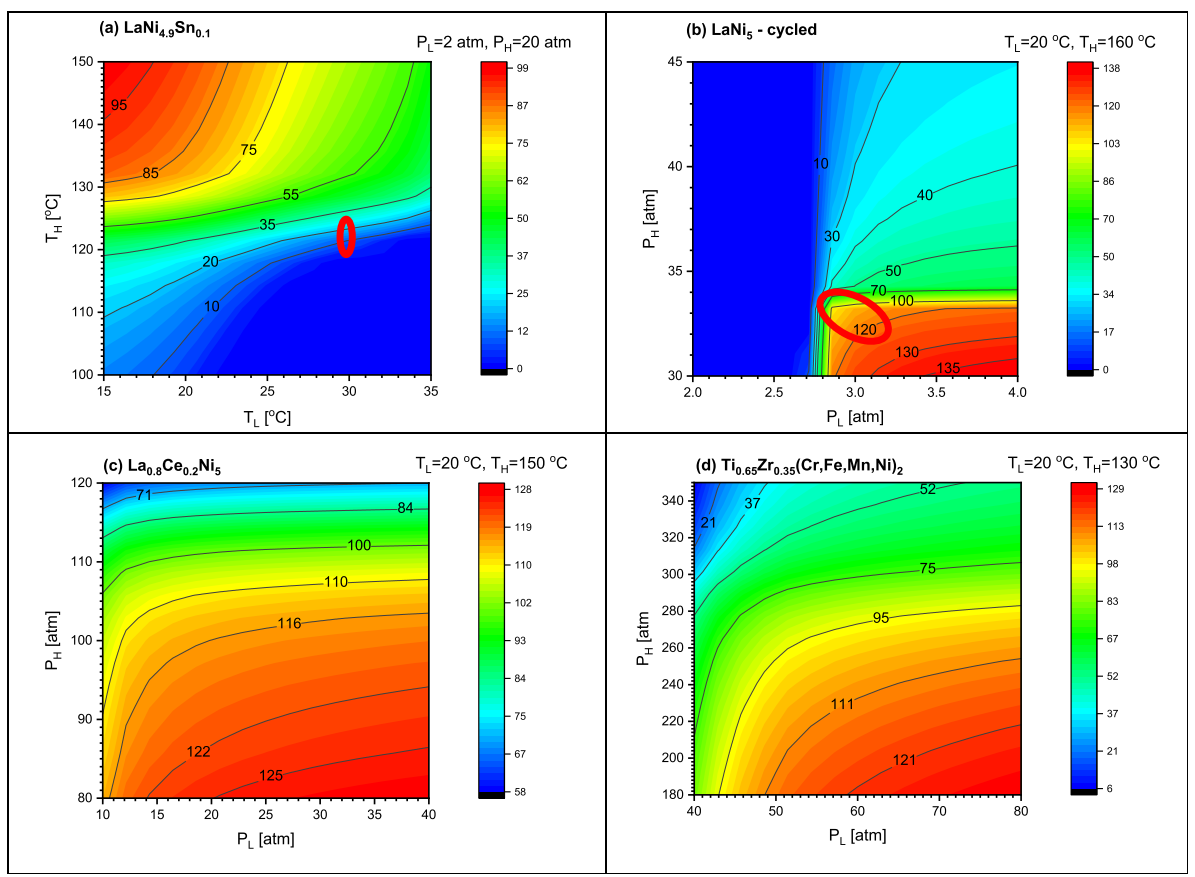

Fig. 2 - Calculated cycle productivities [NL/kg] for $\mathrm{AB}_{5}$-type MHs used for the compression of low-pressure hydrogen depending on the cooling/heating temperatures (a) and suction/discharge $\mathrm{H}_{2}$ pressures (b-d). Influence of the process parameters on the cycle productivity for the regions circled in (a) and (b) is shown in detail in Fig. 3.

alloy ([20]; see Table 1) results in dramatic changes in the hydrogen compression performance (compare Fig. 2(b) with Fig. S8(f)). For the uncycled as-produced alloy material the cycle productivities of $\mathrm{H}_{2}$ compression between 3.5 and $35 \mathrm{~atm}$ are higher than $100 \mathrm{NL} / \mathrm{kg}$ at $\mathrm{T}_{\mathrm{H}}>122^{\circ} \mathrm{C}$, independently on the cooling temperature when it is in a range between 10 and $30^{\circ} \mathrm{C}$ (Fig. S8(e)) while for the cycled $\mathrm{LaNi}_{5}$ this performance can be achieved only at much high temperatures $T_{H}>160{ }^{\circ} \mathrm{C}$ and when $P_{H}<33$ atm (Fig. 2(b)). At the fixed $T_{L}=20{ }^{\circ} \mathrm{C}$ and $\mathrm{T}_{H}=160^{\circ} \mathrm{C}$, the influence of the operating pressures on the cycle productivity of the cycled $\mathrm{LaNi}_{5}$ changes spasmodically at $P_{L} \sim 3$ atm and $P_{H^{\sim}}$ 30 atm for the cycled material (Fig. 2(b)) while even at the lower heating temperature $\left(T_{H}=140^{\circ} \mathrm{C}\right)$ the as-produced alloy provides a very high (>135 NL/kg) productivity when starting from $P_{L}>2$ atm (Fig. S8(f)). The rate of changing $\Delta C$ sharply changes when either absorption $\left(P_{L}, T_{L}\right)$ or desorption $\left(P_{H}, T_{H}\right)$ conditions are close to the plateau areas at pressures close to $P_{L}$ (absorption at $T=T_{L}$ ) or $P_{H}$ (desorption at $T=T_{H}$ ) resulting in significant changes of $C_{A}$ or $C_{D}$ following even minor variations of the temperatures or pressures. As it can be seen from Fig. 3(a), the decrease of the desorption temperature by only $3^{\circ}$ results in a drop of the cycle productivity of $\mathrm{LaNi}_{4.9} \mathrm{Sn}_{0.1}$ in more than two times at fixed $\mathrm{H}_{2}$ charge and discharge pressures.

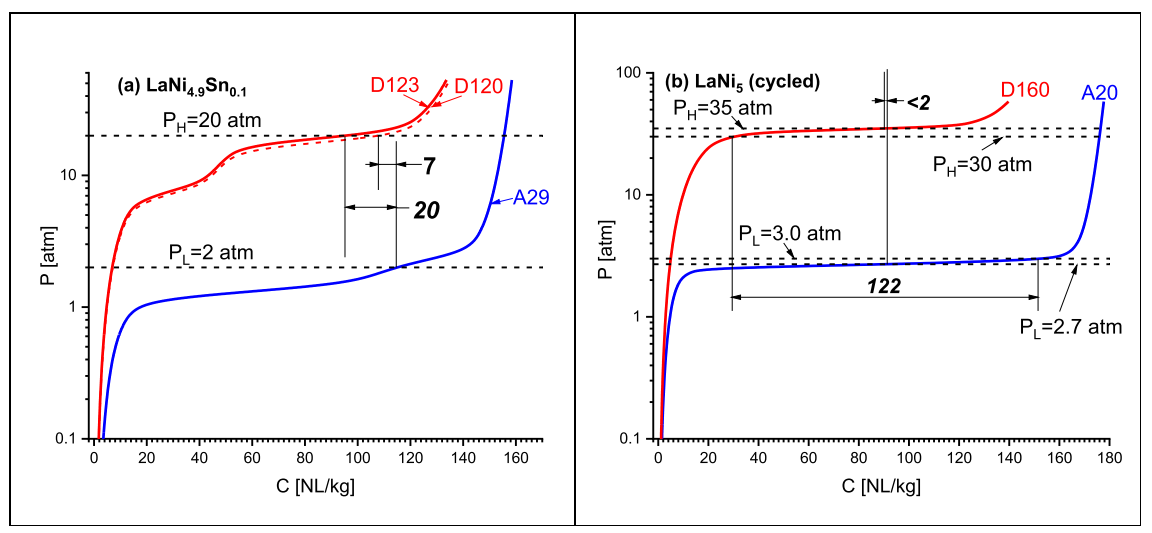

Fig. 3 - Hydrogen absorption (A) and desorption (D) isotherms (temperature in ${ }^{\circ} \mathrm{C}$ are given as labels) used for the determination of cycle productivities for $\mathrm{H}_{2}$ compression using $\mathrm{LaNi}_{4.9} \mathrm{Sn}_{0.1}$ (a; circled region in Fig. 2(a)) and cycled LaNi $(\mathrm{b}$; circled region in Fig. 2(b)). The cycle productivities are shown in bold italic as the differences in hydrogen concentrations at $\left(P_{L}, T_{L}\right)$ and $\left(P_{H}, T_{H}\right)$. 


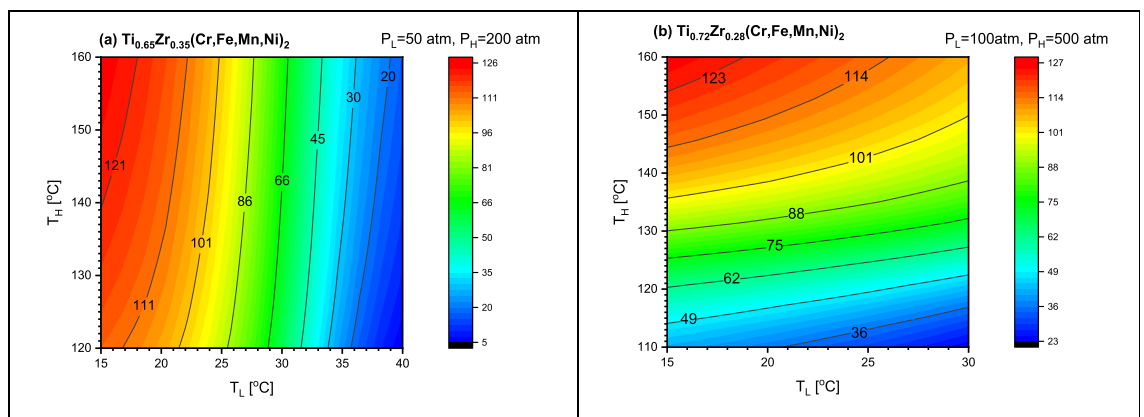

Fig. 4 - Calculated cycle productivities [NL/kg] for $\mathrm{AB}_{2}$-type MHs used for the high-pressure hydrogen compression depending on the cooling/heating temperatures.

Dramatic changes of the cycle productivity take place when the plateaux have an "ideal" flat shape while the operating pressures are close to the plateaux pressures. This feature is illustrated in Fig. 3(b) presenting hydrogen absorption $\left(T_{L}=20^{\circ} \mathrm{C}\right)$ and desorption $\left(T_{H}=160^{\circ} \mathrm{C}\right)$ isotherms for the cycled $\mathrm{LaNi}_{5}$. A drop of the cycle productivity from $>120 \mathrm{NL} / \mathrm{kg}$ (75\% of the full hydrogen capacity) to almost zero is observed when the suction pressure decreases from 3.0 to $2.7 \mathrm{~atm}$ and the discharge pressure increases from 30 to $35 \mathrm{~atm}$.

In our earlier review publication [9] we have shown that use of $\mathrm{MH}$ materials with flat plateaux is very much superior compared to the hydrides with incline plateaux, with compression ratio dropping in several times for inhomogeneous alloys having incline isotherms. On the other hand, the present study shows that for the materials having flat plateaux on pressure - composition isotherms their hydrogen compression performances are much more sensitive to the changes of the operating pressure - temperature conditions than for the alloys with incline isotherms, particularly, when the operating hydrogen pressures are close to the plateau pressures. Thus, fine tuning and control over the P-T conditions for both low $\mathrm{T}$ and high $\mathrm{T}$ levels is required to reach the best compression performance.

The main reason of the sloping plateaux in metalhydrogen systems with multicomponent alloys is a compositional inhomogeneity of the parent alloy $[27,28]$. The compositional inhomogeneities causing a plateau slope increase with the increase of the number of the alloy components (particularly, if the introduced additive significantly alters thermal stability of the corresponding hydride) and decrease after annealing of the alloys [27]. One example is $\mathrm{TiMn}_{2-\mathrm{x}} \mathrm{AB}_{2}$ type alloys [29], where the plateau slope strongly depends on the alloy preparation route and increases in the series "castannealed $\approx$ quench-annealed < as cast < melt quenched". Thus, when selecting the $\mathrm{H}_{2}$ compression material it is important to control a plateau slope by the altering the material preparation route. Use of a reasonable small number of alloy components in combination with annealing is recommended for the increase of compression ratio via achievement of flat plateau. Conversely, if a stable operation at varying pressure/temperature conditions (via sloping plateau) is necessary, it is better to use an as-cast or a melt quenched multicomponent alloy characterised by a significant plateau slope: rapidly solidified $\mathrm{La}_{0.92} \mathrm{Ce}_{0.08} \mathrm{Ni}_{5}$ (see Table 1 ) is a typical example.

Generally, the observed behaviours for the medium(Fig. 2(c), Fig. S9) and high- (Figs. 2(d), Figure 4, Fig. S10) pressure $\mathrm{MH}$ materials show similar trends as were found for the low-pressure hydrides (Fig. 2(a,b), Fig. S8) when the cycle productivity increases with the increase of $T_{H}$ and $P_{L}$ and the decrease of $P_{H}$ and $T_{L}$. Significant decrease of the productivity is observed when approaching plateau either for absorption (Fig. 4(a)) or desorption (Fig. 4(b)) pressure - temperature conditions. However, due to the sloping plateaux for these materials, the changes of the cycle productivities when changing the process temperatures and pressures become rather continuous with no abrupt variations.

In summary, most of the studied $\mathrm{AB}_{5}-$ and $\mathrm{AB}_{2}$-type $\mathrm{MH}$ materials are able to provide hydrogen compression from 1 to $500 \mathrm{~atm}$, with a cycle productivity about $100 \mathrm{NL} / \mathrm{kg}$ and compression ratio up to 10 at $\mathrm{H}_{2}$ suction pressure below 10-15 atm, or up to 5 at the higher suction pressures (see Fig. 5).

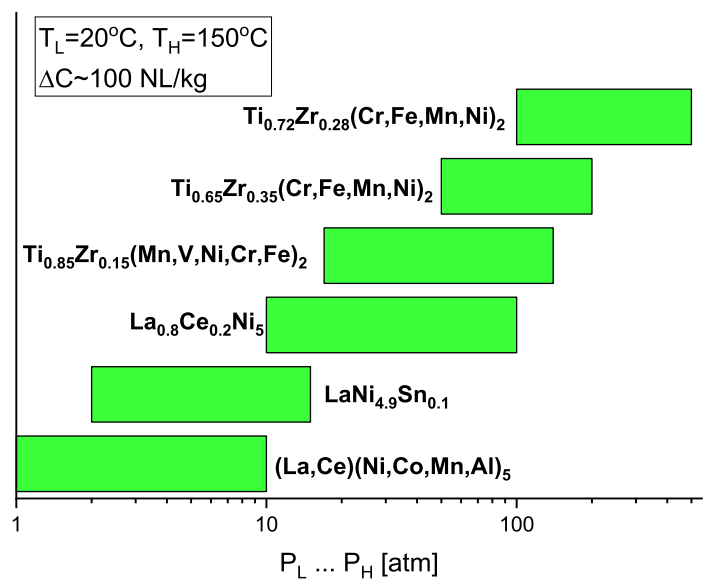

Fig. 5 - Operating pressure ranges for some of the studied MH materials (see also columns 8-9 of Table 1). 
The calculated heat consumptions of the $\mathrm{H}_{2}$ compression (Table 1) were found to be close to the values of the dehydrogenation enthalpies, $\Delta H^{\circ}$. Taking into account approximately linear trend of the increase of the dehydrogenation partial molar enthalpy with hydrogen concentration for the studied $\mathrm{MH}$ (see Fig. S1) this means that the average $\mathrm{H}$ concentration in the $\mathrm{MH}$ during $\mathrm{H}_{2}$ compression process at the specified conditions (Table 1 ) was close to the plateau midpoint. Consequently, the heat consumption of hydrogen compression will increase with the increase of thermal stability of the $\mathrm{MH}$.

The application of the model for the simulation of the performances of single- and multi-stage MHHC's, together with the model validation by comparison of the modelling results with experimental data generated during the tests of industrial-scale metal hydride compressors developed in the authors' institutions, is presented in a related publication (Part II of this work [Lototskyy, Yartys, et al., Int J Hydrogen Energy, https://doi.org/10.1016/j.ijhydene.2020.10.080]). Part II of this work also presents performance forecast for the 30-500 atm $\mathrm{MH}$ compressor presently being developed by the authors.

\section{Conclusions}

- A model for the evaluation of the performances of metal hydride materials for hydrogen compressor has been developed. The model used as an input the data of the PCT diagrams for the hydride forming materials together with operating temperatures and hydrogen pressures.

- The model is capable of calculating (a) cycle productivities of the $\mathrm{MH}$ materials in the compressor, and (b) specific heat consumption for the $\mathrm{H}_{2}$ compression. Importantly, the variations of the performances with the change of the process parameters can be modelled as well.

- Analysis of hydrogen compression performances of three $\mathrm{AB}_{2^{-}}$and six $\mathrm{AB}_{5}$-type intermetallic alloys used in the development of industrial-scale MHHC's at the authors' institutions has been performed. When operating between the temperatures of 20 and $150{ }^{\circ} \mathrm{C}$, these $\mathrm{MH}$ materials were shown to be able to provide $\mathrm{H}_{2}$ compression in the range from 1 to $500 \mathrm{~atm}$, with a cycle productivity about 100 $\mathrm{NL} / \mathrm{kg}$ and compression ratio up to 10 at $\mathrm{H}_{2}$ suction pressure below 10-15 atm, or up to 5 at the higher suction pressures.

- The trends in changing the calculated productivities with the change of operating temperatures and hydrogen pressures have been identified. The cycle productivity of $\mathrm{MH}$ material increases with the decrease of the cooling temperature, decrease of the discharge pressure and increase of the heating temperature together with the increase of the suction pressure. However, when hydrogen pressure approaches plateau pressure for $\mathrm{H}_{2}$ absorption (at the cooling temperature) or plateau pressure for $\mathrm{H}_{2}$ desorption (at the heating temperature), the changes of the cycle productivity become more pronounced. Particularly, these changes become evident when the plateau pressure is flat having a close to "ideal" shape. In the latter case, even minor changes in the operating pressure or temperature result in a dramatic variation of the cycle productivity.

- The heat consumption for the $\mathrm{H}_{2}$ compression increases with the increase of thermal stability of the used $\mathrm{MH}$ material.

\section{Declaration of competing interest}

The authors declare that they have no known competing financial interests or personal relationships that could have appeared to influence the work reported in this paper.

\section{Acknowledgements}

This work is supported by the Department of Science and Innovation of South Africa within Hydrogen South Africa (HySA) program, project KP6-S02.

The international collaboration between South African (MVL, MWD) and Norwegian (VAY, RVD) co-authors was supported by the EU HORIZON2020/RISE Program, project HYDRIDE4MOBILITY.

The international collaboration between South African (MVL, MWD), Russian (BPT) and Chinese (ST) co-authors was supported by BRICS STI Framework Programme, project 064 RICS-MH.

Russian co-authors are grateful to the Ministry of Science and Higher Education of Russian Federation for the financial support (Agreement No. 14.613.21.0087, Unique identifier RFMEFI61318X0087). Chinese co-author was financially supported by MOST (No.2018YFE0100700 \& 2019YFB1505101).

MWD and ML also acknowledge support of National Research Foundation (NRF) of South Africa, grant numbers 116278 (MWD) and 109092 (ML). VAY acknowledges with thanks a support from IFE (project Q-40704).

\section{Appendix A. Supplementary data}

Supplementary data to this article can be found online at https://doi.org/10.1016/j.ijhydene.2020.10.090.

\section{R E F E R E N C E S}

[1] Eriksson ELV, MacA Gray E. Optimization and integration of hybrid renewable energy hydrogen fuel cell energy systems - a critical review. Appl Energy 2017;202:348-64. https:// doi.org/10.1016/j.apenergy.2017.03.132.

[2] Kavadias KA, Apostolou D, Kaldellis JK. Modelling and optimisation of a hydrogen-based energy storage system in an autonomous electrical network. Appl Energy 2018;227:574-86. https://doi.org/10.1016/ j.apenergy.2017.08.050.

[3] Han G, Kwon YK, Kim JB, Lee S, Bae J, Cho EA, et al. Development of a high-energy-density portable/mobile hydrogen energy storage system incorporating an electrolyzer, a metal hydride and a fuel cell. Appl Energy 
2020;259:114175. https://doi.org/10.1016/

j.apenergy.2019.114175.

[4] Weckerle C, Nasri M, Hegner R, Bürger I, Linder M. A metal hydride air-conditioning system for fuel cell vehicles Functional demonstration. Appl Energy 2020;259:114187. https://doi.org/10.1016/j.apenergy.2019.114187.

[5] Giap V-T, Lee YD, Kim YS, Ahn KY. A novel electrical energy storage system based on a reversible solid oxide fuel cell coupled with metal hydrides and waste steam. Appl Energy 2020;262:114522. https://doi.org/10.1016/ j.apenergy.2020.114522.

[6] Cao S, Alanne K. Technical feasibility of a hybrid on-site $\mathrm{H}_{2}$ and renewable energy system for a zero-energy building with a $\mathrm{H}_{2}$ vehicle. Appl Energy 2015;158:568-83. https:// doi.org/10.1016/j.apenergy.2015.08.009.

[7] Apostolou D, Xydis G. A literature review on hydrogen refuelling stations and infrastructure. Current status and future prospects. Renew Sustain Energy Rev 2019;113:109292. https://doi.org/10.1016/j.rser.2019.109292.

[8] Sdanghi G, Maranzana G, Celzard A, Fierro V. Review of the current technologies and performances of hydrogen compression for stationary and automotive applications. Renew Sustain Energy Rev 2019;102:150-70. https://doi.org/ 10.1016/j.rser.2018.11.028.

[9] Lototskyy MV, Yartys VA, Pollet BG, Bowman Jr RC. Metal hydride hydrogen compressors: a review. Int J Hydrogen Energy 2014;39:5818-51. https://doi.org/10.1016/ j.ijhydene.2014.01.158.

[10] Yartys VA, Lototskyy M, Linkov V, Grant D, Stuart A, Eriksen J, et al. Metal hydride hydrogen compression: recent advances and future prospects. Appl Phys A 2016;122:415. https://doi.org/10.1007/s00339-016-9863-7.

[11] Corgnale C, Sulic M. Techno-economic analysis of highpressure metal hydride compression systems. Metals 2018;8:469. https://doi.org/10.3390/met8060469.

[12] Stamatakis E, Zoulias E, Tzamalis G, Massina Z, Analytis V, Christodoulou C, Stubos A. Metal hydride hydrogen compressors: current developments \& early markets. Renew Energy 2018;127:850-62. https://doi.org/10.1016/ j.renene.2018.04.073.

[13] Bellosta von Colbe J, Ares J-R, Barale J, Baricco M, Buckley C, Capurso G, et al. Application of hydrides in hydrogen storage and compression: achievements, outlook and perspectives. Int J Hydrogen Energy 2019;44:7780-808. https://doi.org/ 10.1016/j.ijhydene.2019.01.104.

[14] Hirscher M, Yartys VA, Baricco M, Bellosta von Colbe J, Blanchard D, Bowman Jr RC, et al. Materials for hydrogenbased energy storage - past, recent progress and future outlook. J Alloys Compd 2020;827:153548. https://doi.org/ 10.1016/j.jallcom.2019.153548.

[15] Rusanov AV, Solovey VV, Lototskyy MV. Thermodynamic features of metal hydride thermal sorption compressors and perspectives of their application in hydrogen liquefaction systems. J Phys Energy 2020;2:021007. https://doi.org/10.1088/ 2515-7655/ab7bf4.

[16] Lototskyy M, Klochko Y, Davids MW, Pickering L, Swanepoel D, Louw G, et al. Industrial-scale metal hydride hydrogen compressors developed at the South African Institute for Advanced Materials Chemistry. Mater Today Proc 2018;5:10514-23. https://doi.org/10.1016/ j.matpr.2017.12.383.
[17] Galvis EAR, Leardini F, Ares JR, Cuevas F, Fernandez JF. Simulation and design of a three-stage metal hydride hydrogen compressor based on experimental thermodynamic data. Int J Hydrogen Energy 2018;43:6666-76. https://doi.org/10.1016/ j.ijhydene.2018.02.052.

[18] Zhou Z, Zhang J, Ge J, Feng F, Dai Z. Mathematical modeling of the PCT curve of hydrogen storage alloys. Int J Hydrogen Energy 1994;19:269-73. https://doi.org/10.1016/0360-3199(94) 90097-3.

[19] Fang S, Zhou Z, Zhang J, Yao M, Feng F, Northwood DO. The application of mathematical models to the calculation of selected hydrogen storage properties (formation enthalpy and hysteresis) of $\mathrm{AB}_{2}$-type alloys. Int J Hydrogen Energy 2000;25:143-9. https://doi.org/10.1016/S0360-3199(99)000324.

[20] Tarasov BP, Bocharnikov MS, Yanenko YB, Fursikov PV, Lototskyy MV. Cycling stability of $\mathrm{RNi}_{5}(\mathrm{R}=\mathrm{La}, \mathrm{La}+\mathrm{Ce})$ hydrides during the operation of metal hydride hydrogen compressor. Int J Hydrogen Energy 2018;43:4415-27. https:// doi.org/10.1016/j.ijhydene.2018.01.086.

[21] Lototskyy MV. New model of phase equilibria in metal hydrogen systems: features and software. Int J Hydrogen Energy 2016;41:2739-61. https://doi.org/10.1016/ j.ijhydene.2015.12.055.

[22] Tarasov BP, Fursikov PV, Volodin AA, Bocharnikov MS, Shimkus YY, Kashin AM, Yartys VA, Chidziva S, Pasupathi S, Lototskyy MV. Metal hydride hydrogen storage and compression systems for energy storage technologies, Int $\mathrm{J}$ Hydrogen Energy (available online 6 August 2020); https:// doi.org/10.1016/j.ijhydene.2020.07.085. In press.

[23] Anikina EY, Verbetsky VN. Investigation of the hydrogen interaction with $\mathrm{Ti}_{0.9} \mathrm{Zr}_{0.1} \mathrm{Mn}_{1.3} \mathrm{~V}_{0.7}$ by means of the calorimetric method. Int J Hydrogen Energy 2016;41:11520-5. https://doi.org/10.1016/j.ijhydene.2015.12.126.

[24] Tarasov BP, Bocharnikov MS, Yanenko YB, Fursikov PV, Minko KB, Lototskyy MV. Metal hydride hydrogen compressors for energy storage systems: layout features and results of long-term tests. J Phys Energy 2020;2:024005. https://doi.org/10.1088/2515-7655/ab6465.

[25] Lototskyy M, Davids MW, Swanepoel D, Louw G, Klochko Y, Smith F, et al. Hydrogen refuelling station with integrated metal hydride compressor: layout features and experience of three-year operation. Int J Hydrogen Energy 2020;45:5415-29. https://doi.org/10.1016/j.ijhydene.2019.05.133.

[26] Pickering L, Lototskyy MV, Davids MW, Sita C, Linkov V. Induction melted $\mathrm{AB}_{2}$-type metal hydrides for hydrogen storage and compression applications. Mater Today Proc 2018;5:10740-8. https://doi.org/10.1016/j.matpr.2017.12.378.

[27] Shilov AL, Efremenko NE. Effect of sloping pressure "plateau" in two-phase regions of hydride systems. Russ J Phys Chem 1986;60:3024-8.

[28] Park C-N, Luo S, Flanagan TB. Analysis of sloping plateaux in alloys and intermetallic hydrides I. Diagnostic features. J Alloys Compd 2004;384:203-7. https://doi.org/10.1016/ j.jallcom.2004.04.101.

[29] Semboshi S, Masahashi N, Konno TJ, Sakurai M, Hanada S. Composition dependence of hydrogen absorbing properties in melt quenched and annealed $\mathrm{TiMn}_{2}$ based alloys. J Alloys Compd 2004;379:290-7. https://doi.org/10.1016/ j.jallcom.2004.02.045. 